\title{
Occupational health service - Need for competency development
}

The medical science that has emerged today is mainly to provide care for individuals, which is based on the assumption that Health depended on control of disease. So far the direction of medical education is system is exclusively tilting towards treatment of illness. Occupational Health not only deals with work related disorders/diseases but it also encompasses all factors that affect community health within it. Working conditions and employment have major implications for employee health. The inadequate surveillance of employees is the most important reason for increased prevalence of work related and other non communicable life style diseases at work place.

The expectations of global work force from Occupational Health care are changing continuously with variety of global work situations. The influence from Health and Environmental activists, Proactive legislations and awareness in the Community are really driving changes in occupational health care delivery systems. With changing business scenario, employment and education profile of labor, newer occupations and emerging occupational health challenges the role of Occupational Health Physician has become more demanding and those unable to maintain pace with such developments shall be redundant. The response to such rapid changes in the market from Medical universities and Associations has been luke warm at its best in terms of providing training opportunities in Occupational and Environmental Health.

Hence, there is urgent need for strengthening our skills, developing newer competencies and broadening our knowledge in the area of Occupational and Environmental Health. This kind of business environment and increased expectation from employers and employees, I think time has come to look at competency profile of Occupational Health Professionals. One needs to look at competency model from legislative requirements, Industry needs, employee demands, geographical demands and from Occupational Physician's perspective i.e., Technical and behavioral competencies.

In most countries legislation supports medical surveillance of people working in hazardous operations and maintaining health records. It also demands reporting of notifiable diseases and protective and preventive vaccinations. Thus understanding legal requirements and implementing medical surveillance becomes the basic level competency for medical professional who want to start their career in Industry. The detailed task functions and processes can be defined country and Industry specific.

Most hazardous industries especially those associated with chemicals, petro-chemicals, mines and steel to name a few will need higher skills in Industrial Hygiene, product and process knowledge. Management expects a highly effective internal and external relationship management, and counseling skills from the Medical professional, apart being qualified specialist in Occupational Medicine. Hence planning, implementation and evaluation becomes grade I level competency from industry's perspective.

Looking from employee's expectations, cure or quick relief from disease, disorder or injury is most rewarding to them. Physician needs fair level of clinical knowledge, ability to respond to emergency situations and good counseling and Health education skills. He may have to give extended family care and in a position to organize help at distant places and geographic locations. Even handling of multi cultured employee groups in multinationals is a challenging task and needs humanistic attitude and respect and understanding of cultural value of the organization. This helps him to build up trust and credibility in the Occupational health care delivery system. It is appropriate to term such competencies as transitional competencies as they are required at all levels of operation as of now and in future Occupational Health special-

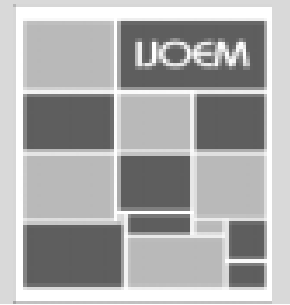


ists may not require all the above competency.

Now let us look from Physician's need to excel in his job, what set of competencies needs to be developed? It depends on at what level of practice of occupational health he intends to carry out, to quote some levels, General Family Physician, General Family Physician with special interest in $\mathrm{OH}$, Company Medical officers and full time retainers, Qualified $\mathrm{OH}$ specialists running private set ups and those in Government organization, $\mathrm{OH}$ specialists in medical college and University set up, $\mathrm{OH}$ specialist in $\mathrm{R} \& \mathrm{D}$ institutes. But at a company level, Diploma level training in occupational medicine with special skills in $\mathrm{OH}$ policy, Interventional strategies for better human performance, Risk communication, Ergonomics Epidemiology and Safety is all that matters. Behavioral skills such as Inter personal relationship skills, Public relation skills, Listening skills, Presentation and communication skills, Liaison and Networking Skills and training skills are very essential for effective performance. In this context competency levels can vary from Grade II to Grade V depending upon what kind of combination of skills one is looking for effective performance and at what level of functioning in the organization.

Many organizations need to do a position clarification exercise for occupational health physician, define performance parameters for occupational Health practice, identify gap levels in skills and training need assessment for Occupational Health Physicians. It is also desirable that we put in place competency levels for Paramedics and other staff who are integral part of OHS management. A competency based OHS can respond with greater compassion, deliver quality care and create supportive environment for positive health. Investing in employee health has always resulted in increased human performance in employee-focused organization. The competency profile can undergo change in the future in tune with business and employee expectations and societal changes. There is more to think and develop on this subject and I expect overwhelming response from my professional colleagues.
G. K. Kulkarni Editor - IJOEM 